\title{
Ailesel akdeniz ateşi ön tanılı hastalarda MEFV mutasyonlarının gerçek zamanlı polimeraz zincir reaksiyonu ve yeni nesil dizileme ile karşılaştırmalı analizi-tek merkez deneyimi
}

\author{
Comparative analysis of MEFV mutations in patients with familial mediterranean fever \\ by real time polymerase chain reaction and next generation sequencing-single center \\ experience
}
Onur Tokgün, Samet Türel, Pervin Elvan Tokgün, Taner Durak, Nedim Karagenç, Aydın Demiray, Hakan Akça

\section{Öz}

Amaç: Ailesel Akdeniz Ateşi (AAA), Akdeniz kökenli popülasyonlarda sıklıkla görülen otoinflamatuvar bir hastalıktır. MEFV genindeki mutasyonların, FMF'nin gelişiminin temelini oluşturduğu saptanmıştır. Bu nedenle, bu çalışmada MEFV mutasyonlarının tespitinde yeni nesil dizileme ve polimeraz zincir reaksiyonu yöntemlerinin olası farklııılarını araştırmayı amaçladık.

Gereç ve yöntem: Bu çalışma 01.08.2018-12.03.2020 tarihleri arasında toplanan örnekler üzerinde Pamukkale Üniversitesi Hastanesi Tıbbi Genetik Anabilim Dalı'nda gerçekleştirilmiştir. MEFV mutasyon analizleri, yeni nesil dizileme ve polimeraz zincir reaksiyonu yöntemleri kullanılarak yapılmış̧ır. Yeni nesil dizileme analizleri sonucunda saptanan MEFV varyantlarının analizi Sophia DDM 5.2.1® platformu kullanıımışır.

Bulgular: MEFV mutasyon analizleri $341 \mathrm{FMF}$ ön tanılı hasta üzerinde gerçekleştrilmiştir. Polimeraz zincir reaksiyonu sonuçlarına göre, hastaların 227'sinde (227/341) herhangi bir MEFV mutasyonu saptanmamış iken 114 hastada yalnızca bir heterozigot mutasyonun varlığı tespit edilmiştir. Allel sayıları ve frekansları değerlendirildiğinde, en sık saptanan varyantlar sırasıyla M694V (46/341), E148Q (45/341), M680I (12/341), V726A (6/341) ve P369S (5/341) olmuştur. Ayrıca, 41 hastada polimeraz zincir reaksiyon analizinden farkı olarak yeni nesil dizileme ile yeni mutasyonlar saptanmıştır.

Sonuç: Mevcut çalışmanın sonuçları, NGS analizinin nadir MEFV varyantlarının yanı sıra FMF hastalarında sıklıkla gözlenen $M E F V$ varyantlarının etkin bir şekilde tespit edilmesine olanak sağladığını göstermektedir. Özetle, hekimlere, moleküler tanı ve genetik test sonuçlarının hastalığın ilerlemesi ile ilişkisini belirlemek için yeni nesil dizileme gibi kapsamlı moleküler testler yapmanın gerekliliğini önermekteyiz.

Anahtar kelimeler: FMF, MEFV, yeni nesil dizileme, gerçek zamanlı PZR.

Tokgün O, Türel S, Tokgün PE, Durak T, Karagenç N, Demiray A, Akça H. Ailesel akdeniz ateşi ön tanılı hastalarda MEFV mutasyonlarının gerçek zamanlı polimeraz zincir reaksiyonu ve yeni nesil dizileme ile karşılaştırmalı analizi-tek merkez deneyimi. Pam Tıp Derg 2021;14:638-644.

\section{Abstract}

Purpose: Familial Mediterranean Fever (FMF) is an autoinflammatory disease which is frequently seen in populations of Mediterranean origin. Mutations in the MEFV gene were found to underlie the development of FMF. Therefore, in this study we aimed to investigate the possible differences of next generation sequencing and polymerase chain reaction methods for the detection of MEFV mutations.

Onur Tokgün, Dr. Öğr. Üye. Pamukkale Üniversitesi, Tıp Fakültesi, Tıbbi Genetik Anabilim Dalı, Denizli, Türkiye, e-posta: otokgun@pau.edu.tr (https://orcid.org/0000-0003-0537-9032) (Sorumlu Yazar)

Samet Türel, Biyolog, Pamukkale Üniversitesi, Tıp Fakültesi, Tıbbi Genetik Anabilim Dalı, Denizli, Türkiye, e-posta: sturel@ pau.edu.tr (https://orcid.org/0000-0003-2282-5938)

Pervin Elvan Tokgün, Biyolog, Pamukkale Üniversitesi, Tıp Fakültesi, Tıbbi Genetik Anabilim Dalı, Denizli, Türkiye, e-posta: parslan@pau.edu.tr (https://orcid.org/0000-0001-9025-4140)

Taner Durak, Dr. Öğr. Üye. Pamukkale Üniversitesi, Tıp Fakültesi, Tıbbi Genetik Anabilim Dalı, Denizli, Türkiye, e-posta: tdurak@pau.edu.tr (https://orcid.org/0000-0001-6143-1670)

Nedim Karagenç, Dr. Öğr. Üye. Pamukkale Üniversitesi Tıp Fakültesi, Tıbbi Genetik Anabilim Dalı, Denizli, Türkiye, e-posta: nkaragenc@pau.edu.tr (https://orcid.org/0000-0002-8255-6621)

Aydın Demiray, Dr. Öğr. Üye. Pamukkale Üniversitesi Tıp Fakültesi, Tıbbi Genetik Anabilim Dalı, Denizli, Türkiye, e-posta: ademiray@pau.edu.tr (https://orcid.org/0000-0002-3343-0184)

Hakan Akça, Prof. Dr. Pamukkale Üniversitesi Tıp Fakültesi, Tıbbi Genetik Anabilim Dalı, Denizli, Türkiye, e-posta: hakca@ pau.edu.tr (https://orcid.org/0000-0002-9477-8571) 
Materials and methods: This study was carried out in Pamukkale University Hospital Department of Medical Genetics on samples collected between 01.08.2018-12.03.2020. MEFV mutation analysis was performed by using next generation sequencing and polymerase chain reaction methods. Sophia DDM 5.2.1® platform was used for the detection of the MEFV variants by next generation sequencing analysis.

Results: MEFV mutation analyses were performed on $341 \mathrm{FMF}$ pre-diagnosed patients. According to polymerase chain reaction results, two hundred and twenty-seven (227/341) of patients had no detectable MEFV mutations and 114 patients had only one heterozygous mutations. When allele numbers and frequencies were evaluated, the most frequently detected variants were M694V(46/341), E148Q(45/341), M680I(12/341), V726A(6/341) and P369S(5/341), respectively. Additionally, new mutations in 41 patients have been observed with next generation sequencing in discordance with polymerase chain reaction analysis.

Conclusion: The results of the current study suggest that NGS analysis enable efficient detection of rare MEFV variants as well as the MEFV gene variants frequently observed in FMF patients. Finally, we recommend the physicians the necessity of running molecular tests to identify the exact genotype, and its correlation with disease progression.

Key words: FMF, MEFV, next generation sequencing, real time PCR.

Tokgun O, Turel S, Tokgun PE, Durak T, Karagenc N, Demiray A, Akca H. Comparative analysis of MEFV mutations in patients with familial mediterranean fever by real time polymerase chain reaction and next generation sequencing-single center experience. Pam Med J 2021;14:638-644.

\section{Giriş}

Ailevi Akdeniz ateşi (FMF), özellikle Türkler, Araplar, Yahudiler ve Ermeniler gibi Akdeniz toplumlarını etkileyen çoğunlukla otozomal resesif kalıtım modeli gösteren bir hastalıktır (MIM 249100) [1, 2]. Bu popülasyonlardaki taşıyıcılık oranları 6'da 1'e kadar çıkabilmektedir. FMF, görünürde sebepsiz ateş atakları, karın veya göğüs ağrısı ve artrit ile karakterize otoinflamatuar bir hastalıktır [3]. Profilaktik kolşisin tedavisi genellikle böbrek yetmezliğine ve diğer organ hasarına yol açabilen amiloidozu önlemek için tercih edilmektedir. Hastalığa, pyrin'i (veya marenostrin) kodlayan MEFV genindeki mutasyonlar neden olmaktadır [4]. Pyrin'in polimorfonükleer hücrelerde inflamasyonun alt düzenleyicisi olarak rol oynadığı öngörülmektedir. FMF aktivitesi olan hastalarda üretilen çeşitli pyrin formları, nötrofil aktivasyonunun uygunsuz şekilde tetiklenmesine ve kontrolsüz interlökin-1 (IL1) salınımına neden olarak, periton, plevra ve eklemlerde inflamasyon epizodlarına yol açmaktadır. Klinik görünümdeki varyasyon ve amiloidoz gelişimi, MEFV mutasyonlarına bağlı olarak değişebilmektedir [5, 6].

FMF'den sorumlu olan MEFV geni 1997'de pozisyonel klonlama yöntemi ile tanımlanmıştır. MEFV geni 16p13.3 lokasyonunda yer alır ve 10 ekzon ile 781 kodondan oluşmaktadır [7]. MEFV geninde yaklaşık olarak 400 adet tanımlanmış mutasyon bulunmaktadır. Bu, mutasyonların çoğu, 680 ve 761 amino asitleri arasında yer alan ekzon 10'da bulunmaktadır.
Ekzon 10'da görülen M694V, V726A, M694I ve M680I mutasyonları ve ekzon 2'de gözlenen E148Q mutasyonları yaklaşık olarak hastaların \%80'inde görülmektedir [8]. FMF'in tipik semptomları homozigot ya da bileşik heterozigot M694V veya M680I mutasyonu görülen olan hastalarda daha şiddetli görülmektedir [9]. E148Q veya $V 726 A$ mutasyonları daha hafif bir klinik seyir ile ilişkilendirilmiştir.

MEFV geninde saptanan mutasyonların sayısı, kullanılan tetkik yönteminin tarihsel gelişimiile doğru orantıııdır. Geçmiş yıllardatercih edilen RFLP ve strip bazlı test yöntemleri yeni MEFV mutasyonlarını saptayabilmek açısından yeterli olmamaktadır. Öte yandan, MEFV mutasyonlarını analiz eden laboratuvarlarda genellikle önceden bahsedilen ve sık gözlendiği bilinen 5 mutasyonu taramaya yönelik (pirosekans ve PZR tabanlı) teknolojilerdir. Farklı klinik seyre sahip hastalarda olası farklı mutasyonların tanımlanmasının tanı koyma ve alternatif tedavi stratejileri üretilmesi noktasında katkı sağlayabileceği düşünülmektedir. $\mathrm{Bu}$ nedenle, sık gözlenen beş MEFV mutasyonundan başka olası yeni mutasyonları saptayabilmek amacıyla MEFV tüm gen yeni nesil dizileme (NGS) teknolojisinin kullanılması önemli bir gelişmedir. Bu bilgiler doğrultusunda, gerçekleştirdiğimiz çalışmada gerçek zamanlı polimeraz zincir reaksiyonu (PZR) yöntemi ile sık gözlenen 5 mutasyonun taramasının yapıldığı ve homozigot veya bileşik heterozigot mutasyon taşımayan bireylerde MEFV geni NGS ile analiz edilmiştir. PZR yönteminden 
elde edilen veriler ile NGS verileri kıyaslanarak mutasyon saptanmasında olası yöntemsel farkıııklar ortaya konması amaçlanmıştır. Öte yandan, MEFV genini taradığımız 341 adet hastada gözlenen mutasyonların türleri ve frekansları analiz edilecektir.

\section{Gereç ve yöntem}

Bu çalışma, 2018 Ocak-2020 Mayıs ayları arasında Pamukkale Üniversitesi Hastanesine karın ağrısı, eklem ağrısı ve ateş vb şikâyetlerle başvuran ve FMF ön tanısı ile MEFV genetik testi gerçekleştirilen 341 adet hastanın dahil edildiği retrospektif bir çalışmadır. Gerçekleştirilecek genetik test öncesi tüm hastalardan bilgilendirilmiş onam formunu okuyup imzalamaları istenmiş ve çalışma için Pamukkale Üniversitesi Tıp Fakültesi Girişimsel Olmayan Klinik Araştırmalar Etik Kurulu'ndan onay alınmıştır. Kan örnekleri alınan hastalardan ilk olarak PZR yöntemi ile M694V, E148Q, V726A, M680I ve P369S mutasyonları analiz edildi. Bu analiz sonucunda homozigot veya bileşik heterozigot mutasyon taşımayan bireylere NGS analizi ile tüm gen analizi gerçekleştirildi.

\section{MEFV mutasyon analizi}

Hastalardan alınan tam kan (2-5 ml) etilendiamintetraasetik asit içeren tüplerde toplandı. Periferik kan hücrelerinden genomik deoksiribonükleik asit (DNA), üreticinin talimatlarına göre QIAamp Kan Kiti (QIAGEN $\mathrm{GmbH}$, Hilden, Almanya) kullanılarak izole edildi. İzole edilen DNA örneklerinden M694V, E148Q, V726A, M680I ve P369S mutastonlarına ait mutant probları içeren miks ile yabanıl tip genotipe ait probları içeren miksler (Genmark, Türkiye) kullanılarak allel spesifik gerçek zamanlı PZR (ASO) reaksiyonu gerçekleştirildi. Kit içerisinde mutasyon analizleri için FAM işaretli problar kullanılmıştır. PZR analiz sonuçları, her bir kuyucuktaki amplifikasyon ve erime eğrisi sıcaklıklarına göre analiz edilmiştir.

NGS ile MEFV mutasyonu taranması, FMF MASTR Dx Assay (Multiplicom) kiti kullanılarak, Illumina MiSeq® platformunda gerçekleştirildi. $\mathrm{Bu}$ yöntem ile ekzon- intron birleşim bölgeleri de dahil olmak üzere MEFV genine ait tüm kodlayan diziler analiz edilmiştir. Dizileme işlemi sonrası elde edilen sekans verileri "Sophia DDM 5.2.1@" analiz programı kullanılarak "hg19 insan genomu" ile karşılaştırılmıştır. In silico analiz, yeni mutasyonlar için Clinvar, PolyPhen-2, SIFT, 1000 Genomes, GnomAD ve Mutation Taster kullanılarak gerçekleştirildi. INFEVERs veritabanına göre $M E F V$ varyantları, mutasyon veya polimorfizm olarak tanımlanmıştır.

\section{İstatistiksel analiz}

İstatistiksel analizler SPSS sürüm 19.0 yazılımı (SPSS Inc., ABD) kullanılarak gerçekleştirildi. Yaygınlık oranları yüzde olarak ifade edilmiştir.

\section{Bulgular}

341 adet $F M F$ ön tanılı olguda gerçekleştirilen ve 5 adet MEFV (M694V, E148Q, V726A, M680I ve P369S) mutasyonunun tarandığı PZR reaksiyonu sonucunda 229 adet bireyde herhangi bir MEFV mutasyonu saptanmamış iken 114 adet bireyde 1 adet heterozigot mutasyonun varlığı tespit edilmiştir. $\mathrm{Bu}$ nedenle, 341 adet örnekte MEFV tüm gen analizi gerçekleştirilmiştir. Gerçek zamanlı PZR ve NGS ile saptanmış olan tüm mutasyon/ polimorfizm'ler hakkında detaylı moleküler ve klinik sınıflandırmaya dair bilgiler Tablo 1'de verilmiştir. Gerçek zamanlı PZR ile Saptanan heterozigot mutasyonlar gözlenme sıklıklarına göre sırasıyla M694V(46/341), E148Q(45/341), M680I(12/341), V726A(6/341) ve P369S(5/341) olarak gözlenmiştir (Tablo 2).

NGS sonuçlarını M694V, E148Q, V726A, M680I ve P369S varyantları açısından değerlendirdiğimizde PZR ile 1 adet heterozigot mutasyon gözlenen 114 bireyin 106'sında aynı heterozigot mutasyon sekanslama ile de okunmuştur. NGS analizi sonucu heterozigot ya da homozigot olarak saptanmış olan mutasyonların sayıları Tablo 3'te verilmiştir. Öte yandan, 8 adet bireyde ise gerçek zamanlı PZR ile herhangi bir mutasyon saptanmamış iken NGS analizi ile 1'er adet heterozigot mutasyon taşıdıkları saptanmıştır. Ayrıca, 1 olguda ise PZR ile gözlenen $\mathrm{E} 148 \mathrm{Q}$ heterozigot mutasyonu NGS analizi ile saptanmamıştır. NGS analizi tüm gen dizileme verilerini içerdiği için belirtilen 5 mutasyon dışında farklı mutasyonların varlığı da tespit edebilmektedir. NGS analizi sonucunda 1 hastada E148Q/M694V/P369S üçlü heterozigot mutasyonu saptanmıştır. NGS analizi ile saptanan yeni mutasyonlar arasında en sık gözlenen değişim R202Q varyantıdır. 
Tablo 1. Saptanan mutasyon/polimorfizm'ler hakkında detaylı moleküler ve klinik sınıflandırmaya dair bilgiler

\begin{tabular}{|c|c|c|c|c|}
\hline Varyant & $\begin{array}{l}\text { Ekzonik } \\
\text { Lokasyon }\end{array}$ & $\begin{array}{l}\text { Nükleotid } \\
\text { Değişisimi }\end{array}$ & Protein Değişimi & ACMG Sınıflama \\
\hline M694V & 10 & c. $2080 A>G$ & p.Met694Val & Patojenik \\
\hline V726A & 10 & c. $2177 \mathrm{~T}>\mathrm{C}$ & p.Val726Ala) & Patojenik \\
\hline M680I & 10 & c. $2040 \mathrm{G}>\mathrm{A}$ & p.Met680lle & Patojenik \\
\hline $\mathrm{R} 761 \mathrm{H}$ & 10 & c. $2282 \mathrm{G}>\mathrm{A}$ & p.Arg761His & Patojenik \\
\hline A744S & 10 & c. $2230 \mathrm{G}>\mathrm{T}$ & p.Ala744Ser & Patojenik \\
\hline K695R & 10 & c. $2084 A>G$ & p.Lys695Arg & Klinik önemi belirsiz \\
\hline K712Q & 10 & c. $2134 A>C$ & p.Lys712GIn & Klinik önemi belirsiz \\
\hline I591T & 9 & c. $1772 \mathrm{~T}>\mathrm{C}$ & p.lle591Thr & Klinik önemi belirsiz \\
\hline S503C & 5 & c. $1508 C>G$ & p.Ser503Cys & Potansiyel Patojenik \\
\hline P369S & 3 & c. $1105 \mathrm{C}>\mathrm{T}$ & p.Pro369Ser & Klinik önemi belirsiz \\
\hline R408Q & 3 & c. $1223 G>A$ & p.Arg408GIn & Klinik önemi belirsiz \\
\hline G304R & 2 & c. $910 \mathrm{G}>\mathrm{A}$ & p.Gly304Arg & Potansiyel Patojenik \\
\hline E148Q & 2 & c. $442 \mathrm{G}>\mathrm{C}$ & p.Glu148GIn & Klinik önemi belirsiz \\
\hline L110P & 2 & c. $329 \mathrm{~T}>\mathrm{C}$ & p.Leu110Pro & Klinik önemi belirsiz \\
\hline S166L & 2 & c. $497 \mathrm{C}>\mathrm{T}$ & p.Ser166Leu & Klinik önemi belirsiz \\
\hline S141I & 2 & c. $422 \mathrm{G}>\mathrm{T}$ & p.Ser141lle & Klinik önemi belirsiz \\
\hline Asn256Arg & 2 & c.761_764dup & p.Asn256Argfs ${ }^{\star} 70$ & Klinik önemi belirsiz \\
\hline R157L & 2 & $\mathrm{c} .470 \mathrm{C}>\mathrm{T}$ & p.Pro157Leu & Klinik önemi belirsiz \\
\hline
\end{tabular}

Tablo 2. Gerçek zamanlı PZR ile analiz edilen varyantların frekansları

\begin{tabular}{llllll}
\hline & M694V & E148Q & V726A & M680I & P369S \\
Heterozygous & 13,49 & 13,20 & 1,76 & 3,52 & 1,47 \\
\hline
\end{tabular}

R202Q varyantı 97 olguda heterozigot 10 olguda ise homozigot olarak gözlenmiştir. $\mathrm{Bu}$ varyant literatürde Türk toplumlarında M694V'den daha fazla sıklıkta gözlenen bir polimorfizm olduğu bilinmektedir. Diğer yeni gözlenen mutasyonlar arasında G304R varyantı ise 9 bireyde heterozigot olarak saptanmıştır. NGS analizi ile yeni saptanan varyantlar Tablo 3'de sayıları ile birlikte verilmiştir. Yöntemsel olarak kıyaslandığında NGS analizlerinin MEFV mutasyonlarını saptayabilme açısından istsatistiksel anlamda daha güvenli bir test olduğu gözlenmiştir $(p<0,05)$. S166L varyantı ise homozigot olarak sadece bir hastada gözlenmiş nadir varyantlar arasındadır. Ayrıca 2'şer olguda nadir gözlenen A744S ve K695R mutasyonları heterozigot olarak gözlenmiştir. Nadir olarak gözlenen varyantlar arasında yer alan S141I, E148Q ile bileşik heterozigot olarak bir hastada saptanmıştır. Bir olguda nadir gözlenen ASN256ARG varyantı, G304R varyantı ile bileşik heterozigot olduğu saptanmıştır. R202Q polimorfizmi gözlenen bireyleri dahil etmezsek NGS analizi sonucunda 37 bireyde PZR ile analiz edilen M694V, E148Q, V726A, M680I ve P369S varyantları dışında bir varyant tespit edilmiştir. Ayrıca, 7 olguda L100P/
E148Q varyantlarının ve 6 olguda ise G304R/ M694V varyantlarının bileşik heterozigot olarak bulundukları saptanmıştır.

\section{Tartışma}

FMF, otozomal resesif geçişli bir sistemik hastalıktır ve Akdeniz ırklarında özel bir eğilim göstermektedir. MEFV geni alel sıklığında etnik farklııklar olduğu literatürde bilinmektedir. Başta Orta Anadolu olmak üzere bazı coğrafi bölgelerde FMF sıklığının yaklaşık \%1 olduğu ve genel yaygınlığının ise $\% 0,1$ civarında olduğu bildirilmektedir [10]. MEFV geninin FMF hastalığının patogenezinden sorumlu gen olması nedeniyle bu gen üzerinde gerçekleştirilen moleküler analizler tanı açısından oldukça önem arz etmektedir. Moleküler tanı yöntemlerinde gün geçtikçe hızla ilerleyen teknoloji sayesinde ortaya çıkan yenilikler hastalığın patogenezi ile ilişkili olabilecek yeni varyantların tanımlanmasına imkân sağlamaktadır. Moleküler tanı açısından kullanılan yöntemin özgüllüğü ve güvenilirliği elde edilecek verilerin kliniğe yansımasının yorumlanmasında oldukça önemlidir. Bu nedenle, gerçekleştirilen çalışmada sık 
Tablo 3. NGS analizi ile saptanan yeni varyantlar

\begin{tabular}{lll}
\hline & Homozygous & Heterozygous \\
\hline M694V & 1 & 45 \\
E148Q & & 44 \\
V726A & & 6 \\
M680I & 11 \\
P369S & & 4 \\
K712Q & & 4 \\
R202Q & 10 & 97 \\
L110P & & 8 \\
E230K & & 4 \\
S141I & & 2 \\
I591T & & 3 \\
S503C & & 3 \\
R761H & & 4 \\
G304R & & 9 \\
ASN256ARG & & 1 \\
S166L & 1 & \\
R157L & & 2 \\
R408Q & & 2 \\
K695R & & 2 \\
A744S & & 2 \\
\hline
\end{tabular}

gözlenen 5 mutasyon açısından PZR yöntemi ile homozigot ya da bileşik heterozigotluk saptanmaması durumunda NGS analizi ile MEFV tüm gen analizini gerçekleştirilmiştir. Elde edilen NGS ile PZR verileri kıyaslanması ile varyantları saptamada yöntemsel farklılıkları ortaya koymak amaçlanmıştır. Bildiğimiz kadarıyla gerçekleştirdiğimiz çalışma bu hasta sayısında PZR ve NGS verilerini kıyaslayan ilk çalışmadır.

Çalışmamızda, M694V varyantı \%28,15 oranında, $\mathrm{E} 148 \mathrm{Q}$ varyantı ise $\% 18,5$ oranında gözlendi. Elde ettiğimiz bu veriler PZR yönteminde homozigot mutasyon taşıyan bireylerin dahil edilmediğini göz önünde bulundurulursa literatüre benzer niteliktedir. Literatürde farklı çalışmalarla FMF'in de dahil edildiği, sistemik otoinflamatuar klinik bulgusu olan pek çok hasta üzerinde gerçekleştirilen MEFV geni mutasyon analizlerinde NGS analizinin hem yeni varyant tanımlama hem de daha yüksek moleküler tanı özellikleri nedeniyle daha nitelikli veriler sunduğunu rapor etmişlerdir [11, 12]. Ayrıca, Gümüş [13] 2018 yılında gerçekleştirdiği çalışmasında NGS analizi ile PCR analizine kıyasla 3 kat daha fazla miktarda MEFV değişiminin saptandığını rapor etmiştir. Öte yandan bizim çalışmamızda 1 vaka gözlediğimiz E148Q/M694V/P369S üçlü bileşik heterozigotluk oldukça az sayıda gözlenen bileşik heterozigotluklardan biridir.
MEFV geninde gözlenen mutasyonların doz etkisine sahip olduğu bilinmektedir. Bu nedenle, laboratuvarda öncelikle daha düşük maliyetli olan 5 varyantın (M694V, E148Q, V726A, M680I ve P369S) PZR analizi ile kontrol edilmesi ve homozigot ya da bileşik heterozigotluk gözlenmeyen hastalarda NGS analizine geçilmesi stratejisinin moleküler tanı ve hastalığın fenotipinin yorumlanması açısından faydalı olduğunu düşünmekteyiz. Çalışmada elde ettiğimiz verilere göre 41 olguda PZR ile taranan varyantlar dışında yeni bir varyant tespit edilmiştir. Tespit edilen bu varyantlar arasında oldukça nadir gözlenen L110P, E230K, K712Q, S141I, I591T, A744S, K695R ve S166L varyantları yer almaktadır. NGS ile saptanan varyantlar arasında en sık gözlenen R202Q değişiminin bazı yayınlarda Türk popülasyonu için bir polimorfizm olarak hastalığın kliniğinde bir rolü olduğu düşünülmese de Yiğit ve ark. [14] gerçekleştirdikleri araştırmada homozigot R202Q değişiminin klinik açıdan önemli olabileceğini göstermişlerdir. Öte yandan, NGS analizi ile saptanan L110P, E230K, K712Q, S141I, I591T, A744S, K695R ve S166L nadir varyantların klinik açıdan önemli olabileceği literatürde gerçekleştirilen çalışmalar ortaya koymuştur [15-20].

FMF tipik olarak otozomal resesif kalıtım yoluyla geçtiği bilinse de önemli sayıda hasta MEFV genlerinde $1(\leq \% 30)$ veya herhangi 
bir tanımlanabilir mutasyona $(\leq \% 20)$ sahip olmadığı bilinmektedir [21]. Literatürde gerçekleştirilen çalışmalarda özellikle yaygın olarak bilinen gözlendiği M694V, M680I, M694I, V726A ve E148Q değişimlerinin taranması nedeniyle moleküler tanının verimli olarak konmadığı belirtilmiştir. Bu durumun, gerçekleştirilen genetik testlerin çoğunda yaygın olarak gözlemlenen mutasyonları taramak için tasarlandığı ve bu nedenle nadir gözlenen mutasyonların saptanamamasına ve moleküler tanı da yetersizliklere neden olmaktadır. Bu nedenle literatürde son yıllarda NGS tabanlı genetik testlerin daha sıklıkla kullanıldığı belirtilmektedir.

Sonuç olarak, çalışmamızda çalışmada sık gözlenen 5 mutasyon açısından PZR yöntemi ile homozigot ya da bileşik heterozigotluk saptanmaması durumunda NGS analizi ile MEFV tüm gen analizi gerçekleştirilmiştir. Gerçekleştirilen NGS analizi sonucunda 41 olguda PZR yönteminde saptanandan farklı bir varyant tanımlanmıştır. Tanımlanan yeni varyantların Türk popülasyonu üzerinde olası klinik etkinliklerini tanımlayabilmek için daha fazla hasta örneği üzerinde NGS analizi gerçekleştirmek gerekmektedir. Özetle, gerçekleştirdiğimiz NGS analizi sonucunda tanımlanan yeni mutasyonların, tanı ve hastalığın progresyonunu yorumlayabilme açısından katkı sağlayacağını düşünmekteyiz.

Çıkar ilişkisi: Yazarlar çıkar ilişkisi olmadığını beyan eder.

\section{Kaynaklar}

1. Ben Chetrit E, Levy M. Familial Mediterranean fever. Lancet 1998;351:659-664. https://doi. org/10.1016/S0140-6736(97)09408-7

2. Ben Chetrit E, Touitou I. Familial mediterranean Fever in the World. Arthritis Rheum 2009;61:1447-1453. https://doi.org/10.1002/art.24458

3. Shoham NG, Centola M, Mansfield E, et al. Pyrin binds the PSTPIP1/CD2BP1 protein, defining familial Mediterranean fever and PAPA syndrome as disorders in the same pathway. Proc Natl Acad Sci USA 2003;100:13501-13506. https://doi.org/10.1073/ pnas. 2135380100

4. de Jesus AA, Canna SW, Liu Y, Goldbach Mansky R. Molecular mechanisms in genetically defined autoinflammatory diseases: disorders of amplified danger signaling. Annu Rev Immunol 2015;33:823-874. https://doi.org/10.1146/annurevimmunol-032414-112227
5. Kasifoglu T, Bilge SY, Sari I, et al. Amyloidosis and its related factors in Turkish patients with familial Mediterranean fever: a multicentre study. Rheumatology (Oxford) 2014;53:741-745. https://doi. org/10.1093/rheumatology/ket400

6. Fietta P. Autoinflammatory diseases: the hereditary periodic fever syndromes. Acta Biomed 2004;75:92-99.

7. Pras E, Aksentijevich I, Gruberg L, et al. Mapping of a gene causing familial Mediterranean fever to the short arm of chromosome 16. N Engl J Med 1992;326:15091513. https://doi.org/10.1056/NEJM199206043262301

8. Sarı İ, Birlik M, Kasifoğlu T. Familial Mediterranean fever: an updated review. Eur J Rheumatol 2014;1:2133. https://doi.org/10.5152/eurjrheum.2014.006

9. Giancane G, Ter Haar NM, Wulffraat N, et al. Evidencebased recommendations for genetic diagnosis of familial Mediterranean fever. Ann Rheum Dis 2015;74:635-641. https://doi.org/10.1136/annrheumdis-2014-206844

10. Kisacik B, Yildirim B, Tasliyurt $T$, et al. Increased frequency of familial Mediterranean fever in northern Turkey: a population-based study. Rheumatol Int 2009;29:1307-1309. https://doi.org/10.1007/s00296009-0849-z

11. Bozgeyik E, Mercan R, Arslan A, Tozkir H. Nextgeneration screening of a panel of genes associated with periodic fever syndromes in patients with Familial Mediterranean Fever and their clinical characteristics. Genomics 2020;112:2755-2762. https://doi. org/10.1016/j.ygeno.2020.03.012

12. Düzkale Teker N, Öz Ö. AileviAkdenizAteşi hastalarında MEFV geninin NGS ile analizi: tek merkez deneyimi. Harran Üniversitesi Tıp Fakültesi Dergisi 2020;17:454459. https://doi.org/10.35440/hutfd.826687

13. Gumus E. The frequency of MEFV gene mutations and genotypes in Sanliurfa province, south-eastern region of Turkey, after the Syrian civil war by using next generation sequencing and report of a novel exon 4 mutation (1423T). J Clin Med 2018;7:105. https://doi. org/10.3390/jcm7050105

14. Yigit S, Karakus N, Tasliyurt T, Kaya SU, Bozkurt N, Kisacik B. Significance of MEFV gene R202Q polymorphism in Turkish familial Mediterranean fever patients. Gene 2012;506:43-45. https://doi. org/10.1016/j.gene.2012.06.074

15. Endo $\mathrm{Y}$, Koga $\mathrm{T}$, Hara $\mathrm{K}$, et al. The possession of exon 2 or exon 3 variants in the MEFV gene promotes inflammasome activation in Japanese patients with familial Mediterranean fever with a heterozygous exon 10 mutation. Clin Exp Rheumatol 2020;127:49-52.

16. Fisher BAC, Lachmann HJ, Rowczenio D, Goodman HJB, Bhalara S, Hawkins PN. Colchicine responsive periodic fever syndrome associated with pyrin I591T. Ann Rheum Dis 2005;64:1384-1385. https://doi. org/10.1136/ard.2004.030379 
17. Twig G, Livneh A, Vivante A, et al. Mortality risk factors associated with familial Mediterranean fever among a cohort of 1.25 million adolescents. Ann Rheum Dis 2014;73:704-709. https://doi.org/10.1136/ annrheumdis-2012-202932

18. Richards S, Aziz N, Bale S, et al. Standards and guidelines for the interpretation of sequence variants: a joint consensus recommendation of the American College of Medical Genetics and Genomics and the Association for Molecular Pathology. Genet Med 2015;17:405-424. https://doi.org/10.1038/gim.2015.30

19. Cekin N, Akyurek ME, Pinarbasi E, Ozen F. MEFV mutations and their relation to major clinical symptoms of Familial Mediterranean Fever. Gene 2017;626:9-13. https://doi.org/10.1016/j.gene.2017.05.013

20. Soylemezoglu O, Kandur Y, Duzova A, et al. Familial Mediterranean fever with a single MEFV mutation: comparison of rare and common mutations in a Turkish paediatric cohort. Clin Exp Rheumatol 2015;33:152155.

21. Marek Yagel D, Berkun Y, Padeh S, et al. Clinical disease among patients heterozygous for familial Mediterranean fever. Arthritis Rheum 2009;60:18621866. https://doi.org/10.1002/art.24570

Etik kurul onayı: Bu çalışmada Pamukkale Üniversitesi Tıp Fakültesi Girişimsel Olmayan Klinik Araştırmalar Etik Kurulu'nun 19.01.2021 tarih ve 02 sayılı kurul kararı ile onay alınmıştır (E-60116787-020-9706).

\section{Yazarların makaleye olan katkıları}

O.T. çalışmanın ana fikrini ve hipotezini kurgulamıştır. T.D., N.K., A.D. ve H.A. teoriyi geliştirmiş, gereç ve yöntem bölümünü düzenlemişlerdir. Sonuçlar kısmındaki verilerin değerlendirmesini O.T., S.T. ve P.E.T. yapmışlardır. Makalenin tartışma bölümü O.T. tarafından yazıımış, P.E.T. ve S.T. gözden geçirip gerekli düzeltmeleri yapmış ve onaylamışlardır. Ayrıca tüm yazarlar çalışmanın tamamını tartışmış ve son halini onaylamıştır. 